\title{
ANOMALIAS DE CHUVAS E SUA RELAÇÃO COM PARTICULAS TOTAIS EM SUSPENSÃO EM CURITIBA/PR
}

\author{
Francisco Jablinski Castelhano $^{(\mathrm{a})}$;Gabriela Marques Pinheiro $^{(\mathrm{b})}$ \\ (a) Departamento de Geografia, Universidade Federal do Paraná, fjcastelhano@gmail.com \\ (b) Departamento de Geografia, UNICENTRO/ Irati- PR, gabimpinheiro20@ hotmail.com
}

\section{Eixo: CLIMATOLOGIA EM DIFERENTES NÍVEIS ESCALARES: MUDANÇAS E VARIABILIDADES}

\begin{abstract}
Resumo
A má qualidade do ar é um dos grandes problemas ambientais observados em sítios urbanos. Sua gênese encontra-se na associação entre poluentes emitidos e nível de diluição dos mesmos. Estudos apontam este segundo item tem relação direta com as condições meteorologicas do local analisado. Este trabalho tem como objetivo analisar a relação entre o regime de chuvas e os níveis de poluição por Particulas Totais em Suspensão (PTS) na cidade de Curitiba/PR. Para tanto foi calculado o Indice de Anomalias de Chuvas para dez anos (2005 a 2014) de chuva coletados junto à estação meteorologica oficial do INMET da cidade. Estes dados foram correlacionados com a oscilação de PTS coletados no mesmo periodo em três estações oficiais de monitoramento da qualidade do ar dispersas em pontos distintos da região. Os resultados apontaram uma correlação negativa significativa para os três pontos de coleta de PTS da cidade.
\end{abstract}

Palavras chave: Qualidade do Ar, Indice de Anomalia de Chuvas, PTS, Curitiba

\section{Introdução}

A poluição do ar pode ser apontada como um dos principais problemais ambientais enfrentados em ambientes urbanos. Sob a ótica da climatologia, Em seus estudos Monteiro (1976) trata este fenomeno de maneira sistemica, inserindo-o como parte do sistema clima-urbano, e inserindo-o no subcampo fisícoquimico. Segundo o mesmo autor, a gênese deste campo de estudo, diferente dos demais da climatologia urbana, encontra-se exclusivamente na atividade do homem.

Conforme apontado por Hufty (2001) e McCormac (1971), as condições meteorologicas vigentes em um dado sítio são peça-chave apenas no entendimento dos processos de diluição ou dispersão de poluição atmosférica, visto que, estes são apenas uma parte da composição dos níveis de poluição, tendo-se que levar em conta que o fator determinante para isto são os níveis de emissão, que por sua vez estão atrelados diretamente à atividade do homem (AYOADE,1986). 
Neste sentido, a precipitação pluviométrica surge como uma das principais variaveis climáticas que condicionam o acúmulo ou dispersão de determinandos contaminantes atmosféricos, tendo, esta relação, sido abordada por diversos estudos. Kartal e Ozer (1998) e Derisio (2012) justificam tal fato, apontando que tanto a chuva como a umidade do ar, auxiliam nos processos de absorção e deposição principalmente de Material Particulado e Dióxido de Enxofre.

Em estudos realizados por Danni-Oliveira (2000) e Gutjahr (2002) em Curitiba/PR e Paulínia/SP respectivamente deflagram esta relação inversa entre precipitação e níveis de material particulado, contudo não o detalham.

Castelhano e Mendonça (2016) apontaram, contudo uma relação estatistica inversa muito fraca entre chuvas e material particulado em suspensão, dando maior ênfase para a associação entre este poluente e os volumes de umidade relativa do ar.

Tal teoria ainda é muito debatida, tendo sido refutada por Akpinar et al (2009), que apontaram relação oposta entre níveis de umidade relativa do ar, chuva e PTS e SO2 na região leste da Turquia.

Os autores encontraram relação positiva entre a umidade e chuva, indicando neste caso, que níveis mais altos de umidade propiciavam piores condições em termos de qualidade do ar.

Tendo em vista esta associação entre o regime de chuvas e os níveis de poluição, e visando detalha-la, este trabalho se propõe a analisar a relação entre o Indíce de Anomalia de Chuvas (IAC) e os níveis de Particulas Totais em Suspensão (PTS) para a cidade de Curitiba no periodo de Janeiro de 2005 a Dezembro de 2014, totalizando dez anos de dados. Sabe-se da existência de uma sazonalidade na variação dos valores de PTS, contudo, objetiva-se neste trabalho demonstrar uma variação intrasazonal nos valores deste poluente em função de uma possivel relação com o IAC.

\section{Materiais e Métodos}

Para a realização deste estudo foram coletados dados de PTS de três estações de monitoramento da qualidade do ar mantidas pelo Instituto Ambiental do Paraná e dispersas no Aglomerado Urbano de Curitiba (AUC) e apontadas pela figura 1. Cada ponto de coleta escolhido se localiza em uma região distinta da área de urbano, possuindo caracteristicas diferentes que afetam diretamente os valores do poluente.

O PTS caracteriza-se como qualquer particula em suspensão com um tamanho de até $100 \mu$ m. A legislação brasileira (Resolução 003/1990 CONAMA) estabelece os limites aceitaveis primário e secundário, para este poluente como $240 \mu \mathrm{g} / \mathrm{m}^{3}$ e $150 \mu \mathrm{g} / \mathrm{m}^{3}$ em médias de 24 horas.

DOI - $10.20396 /$ sbgfa.v1i2017.2588 - ISBN 978-85-85369-16-3 


\section{OS DESAFIOS DA GEOGRAFIA FÍSICA NA FRONTEIRA DO CONHECIMENTO \\ Instituto de Geociências - Unicamp \\ Campinas - SP \\ 28 de Junho à 02 de Julho de 2017}

Os dados de chuva são provindos da estação meteorologica oficial do SIMEPAR, localizada no campus do Centro Politecnico da UFPR, na região leste da capital paranaense e tambem apontado na figura 1. Estes dados foram coletados em escala horária e tratados primeiramente no software excel.

Optou-se por utilizar o Indice de Anomalia de Chuva de Rooy (1965) expresso pela formulas:

$$
\operatorname{IAC}=3\left[\frac{(\mathrm{N}-\overline{\mathrm{N}})}{(\overline{\mathrm{M}}-\overline{\mathrm{N}})}\right] \quad \text { (1) } \mathrm{e}^{\mathrm{IAC}=-3\left[\frac{(\mathrm{N}-\overline{\mathrm{N}})}{(\overline{\mathrm{X}}-\overline{\mathrm{N}})}\right]}
$$

para anomalias positivas e negativas respectivamente, onde onde $\mathrm{N}$ - precipitação mensal atual (mm.mês-1), $\overline{\mathrm{N}}$ - precipitação média mensal da série histórica (mm.mês-1), $\overline{\mathrm{M}}$ - média das dez maiores precipitações mensais da série histórica (mm.mês-1) e $\bar{X}$ - média das dez menores precipitações mensais da série histórica (mm.mês-1). A classificação da Pluviosidade a partir deste produto encontra-se detalhado na tabela I.

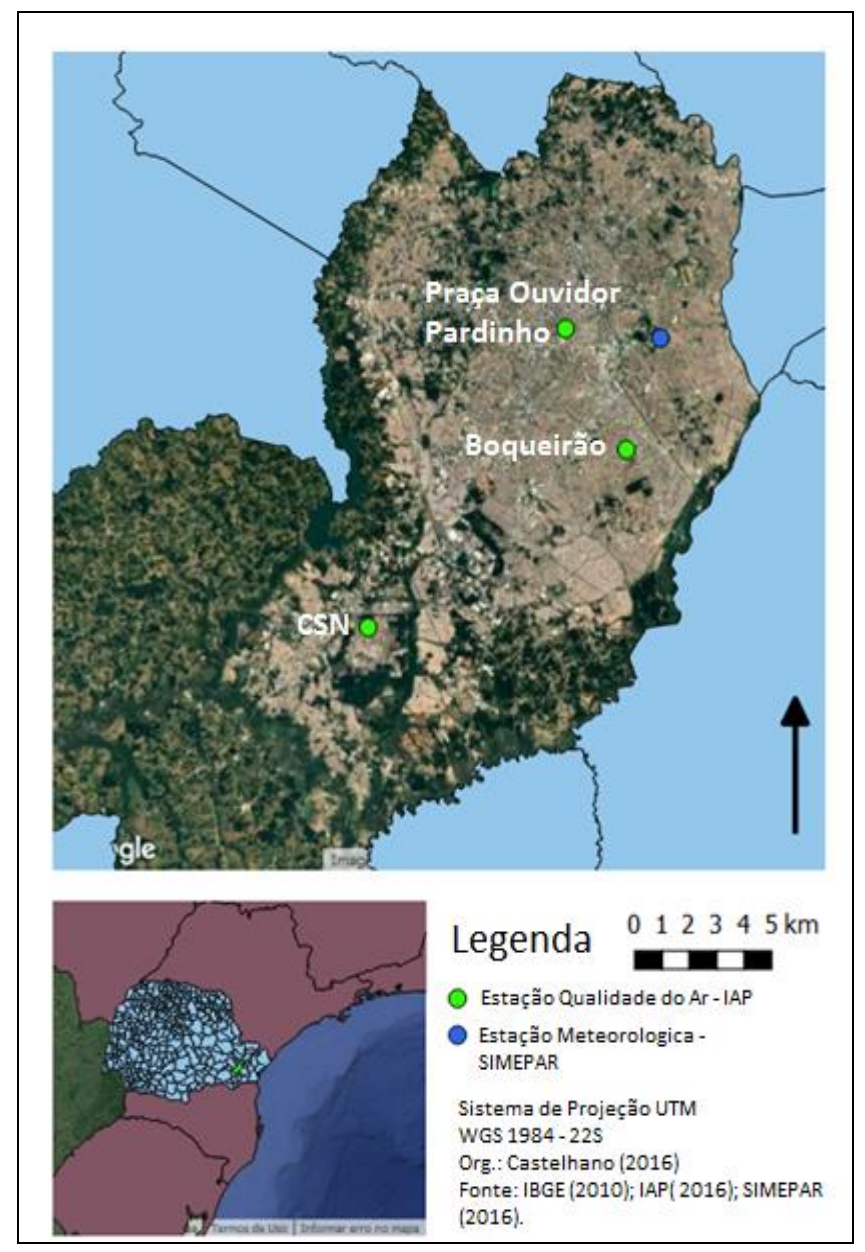


Figura 1 - Localização das Estações de Qualidade do Ar e Meteorologica - Curitiba/PR

Para a realização do calculo do IAC, optou-se por utilizar o pacote para R Precintcon (Povoa e Nery, 2016). Através do mesmo pacote, plotou-se os gráficos sazonais com os indices calculados e as médias mensais de PTS para as três estações possibilitando a análise conjunta das duas variaveis.

Findando a análise, foram realizados calculos de correlação entre o IAC e os valores mensais de poluição por PTS nas três estações de coleta analisadas.

Tabela I - Classificação da Pluviosidade segundo o IAC

\begin{tabular}{|c|c|}
\hline $\begin{array}{c}\text { Valor do Indice de Anomalia de } \\
\text { Chuva (IAC) }\end{array}$ & Classificação da Pluviosidade \\
\hline Maior que 4 & Muito Chuvoso \\
\hline Entre 2 e 4 & Chuvoso \\
\hline Entre 0 e 2 & Neutro \\
\hline 0 & Seco \\
\hline Entre 0 e -2 & Muito Seco \\
\hline Entre -2 e -4 & Extremamente Seco \\
\hline Menor que -4 & \\
\hline
\end{tabular}

Fonte: Rooy (1965)

\section{Resultados e Discussões}

A figura 2 deflagra os valores do índice de anomalia de chuvas em comparação aos valores mensais médios de Particulas Totais em Suspensão para as três estações de coleta as quais tiveram dados analisados.

Os valores do IAC se alternam entre positivos e negativos, de modo que o periodo com maior sequencia de valors negativos se deu entre Abril e Agosto de 2006, portanto cinco meses seguidos, e a maior sequência de valores positivos se sucedeu entre Setembro de 2009 e Abril de 2010, totalizando oito meses seguidos.

Ao todo nestes 120 meses de análise, observou-se 1 mês como "Extremamente chuvoso", 9 como "Muito Chuvoso", 44 como "Chuvoso", 42 classificados como "Seco" e 24 como "Muito Seco". O mês com 


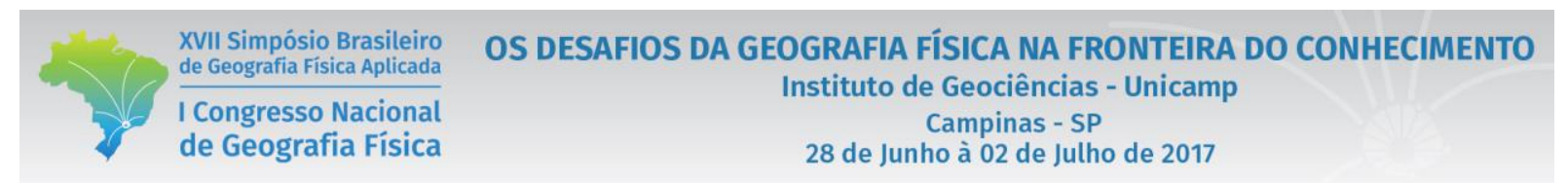

maior valor positivo foi Janeiro de 2010 com 5,15 e aquele com maior valor negativo foi Junho de 2007 com -3.69 .

Os valores de PTS por outro lado, obedecem a uma lógica sazonal ja explicitada por Danni-Oliveira (2000). Os meses de inverno são aqueles em que os valores do poluente encontram-se em seu pico. $\mathrm{Na}$ estação CSN, os meses de Julho de 2007 e Julho de 2013 foram aqueles com maior valor médio deste poluente, com 137,4 $\mu \mathrm{g} / \mathrm{m}^{3}$ e $129,4 \mu \mathrm{g} / \mathrm{m}^{3}$ respectivamente. Igualmente na estação Praça Ouvidor Pardinho, na região central, onde os meses de Julho de 2006 com 62,5 $\mu \mathrm{g} / \mathrm{m}^{3}$ e Julho de 2008 com 56,5 $\mu \mathrm{g} / \mathrm{m}^{3}$ foram os maiores, e na estação Boqueirão onde o mês de Junho de 2007 registrou a maior média do periodo analisado com $101.1 \mu \mathrm{g} / \mathrm{m}^{3}$ seguido pelo mês de Junho de $2011 \mathrm{com} 88,4 \mu \mathrm{g} / \mathrm{m}^{3}$.
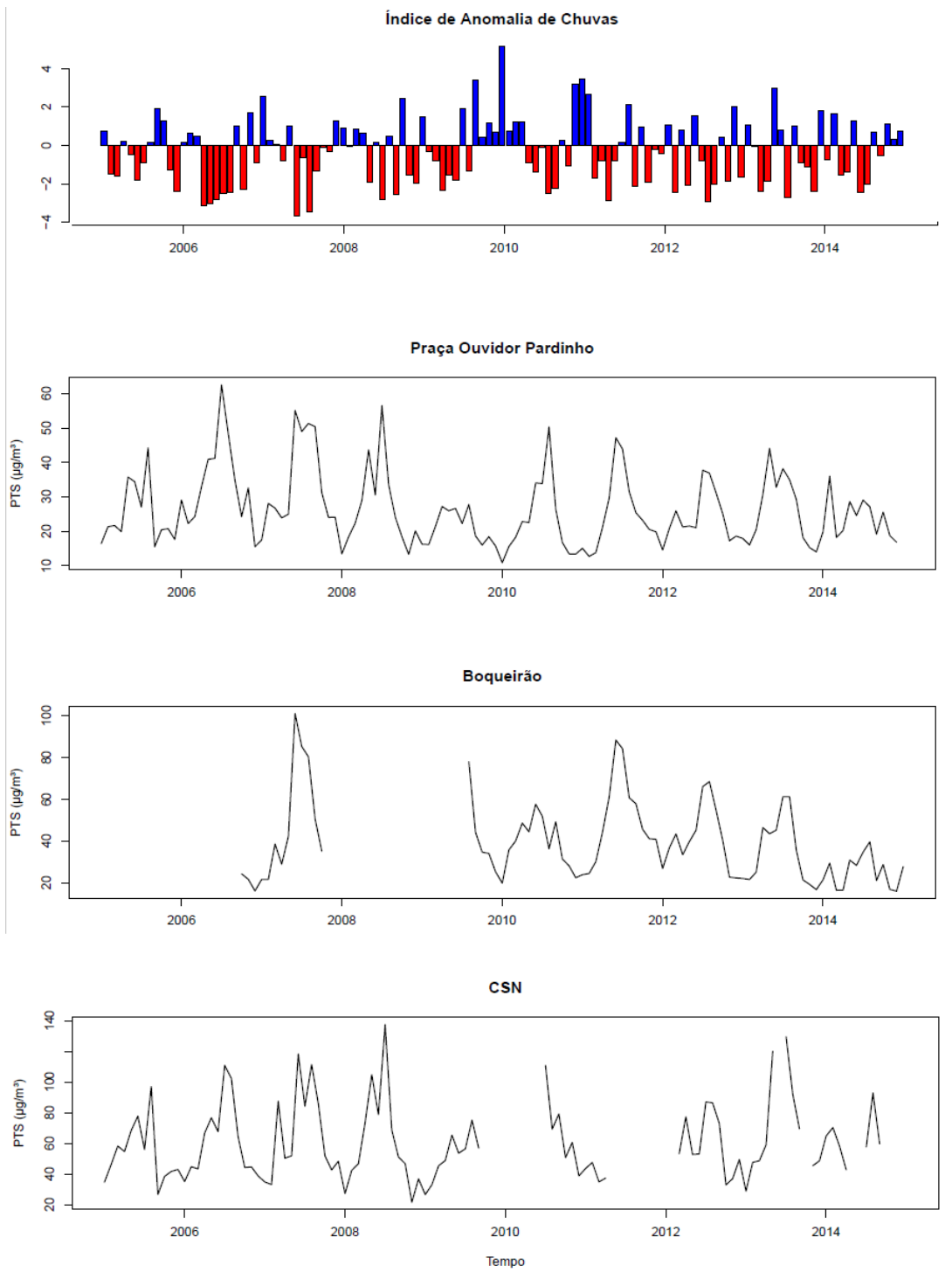


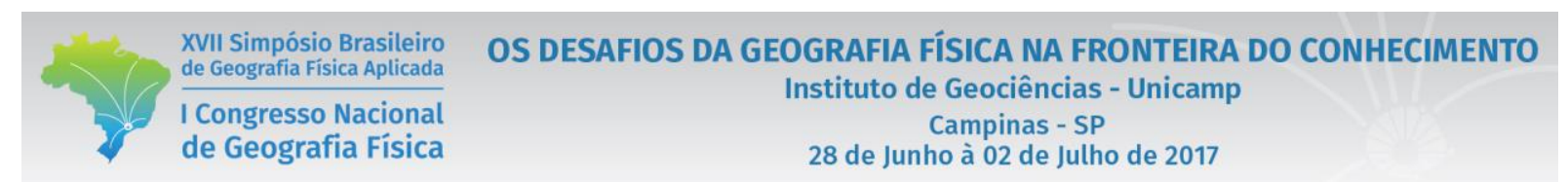

Figura 2 - Indice de Anomalia de Chuvas e Médias Mensais de PTS - Curitiba/PR.

Já os valores mais baixos encontram-se em sua maioria entre o fim da Primavera e o Verão. Na estação CSN, as menores médias sucederam-se nos meses de Novembro de 2008 e Janeiro de 2009 com 21,4 $\mu \mathrm{g} / \mathrm{m}^{3}$ e $26,5 \mu \mathrm{g} / \mathrm{m}^{3}$ respectivamente. Na estação Praça Ouvidor Pardinho foram em Janeiro de 2010 com $10,9 \mu \mathrm{g} / \mathrm{m}^{3}$ e Fevereiro de $2011 \mathrm{com} 14,3 \mu \mathrm{g} / \mathrm{m}^{3}$. A terceira estação, Boqueirão, teve seus menores registros nos meses de Dezembro de 2014 com 16,1 $\mu \mathrm{g} / \mathrm{m}^{3}$ e Dezembro de 2006 com 16,2 $\mu \mathrm{g} / \mathrm{m}^{3}$.

Para melhor observar dita relação, os dados foram reorganizados de modo que os valores do IAC fossem postos em ordem decrescente, reordenando também os valores médios de PTS seguindo a continuidade proposta por esta nova ordem no IAC (Figura 3).
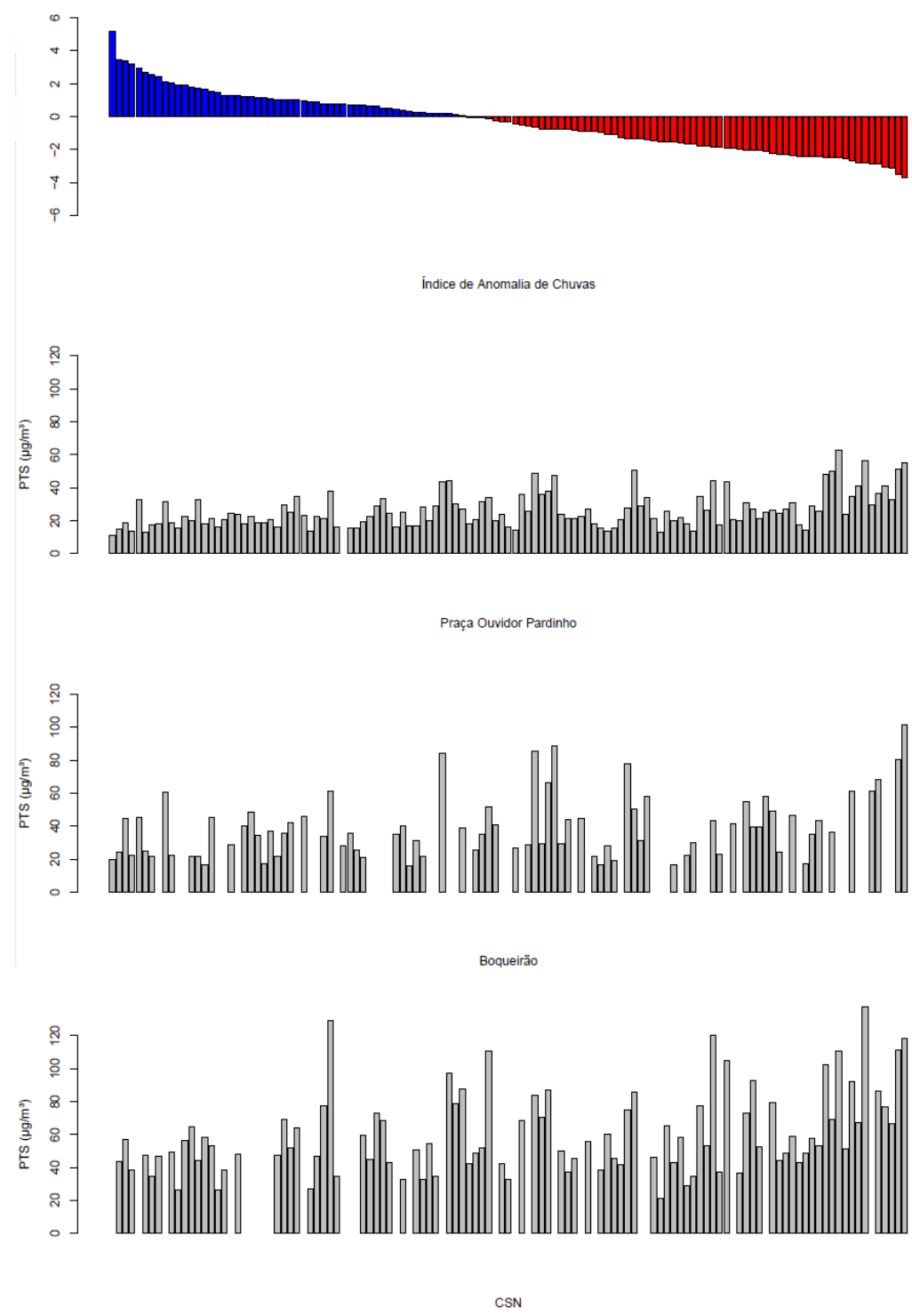

Figura 3 - Indice de Anomalia de Chuvas em ordem decrescente e Médias Mensais de PTS - Curitiba/PR.

DOI - 10.20396/sbgfa.v1i2017.2588 - ISBN 978-85-85369-16-3 


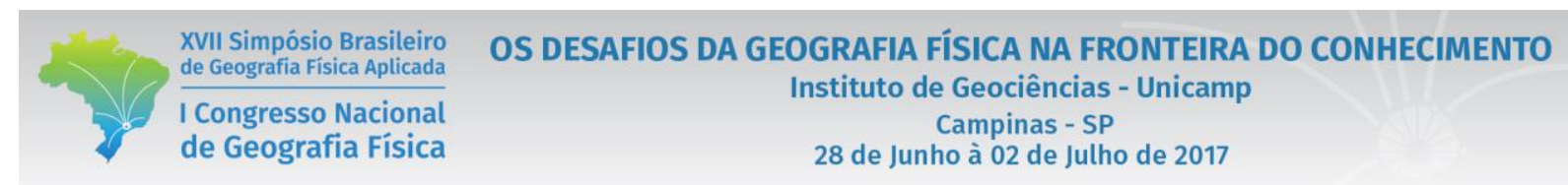

A primeira vista podemos notar uma significativa correlação inversa entre as variaveis abordadas. No caso das estações Boqueirão e CSN os valores de correlação de Pearson calculados ficaram ambos em -0,36, enquanto que no caso do ponto junto a Praça Ouvidor Pardinho ficou em -0,47.

A seguir serão apresentados os mesmos dados reorganizados sazonalmente, a fim de se averiguar a relação entre as anomalias de chuva e o PTS por estação do ano.

A figura 4 deflagra a situação de verão. Percebe-se que, apesar de falhas na série para as estações Boqueirão e CSN, os maiores valores médios de PTS encontram-se sob situação de anomalia negativa de chuva, portanto em meses relativamente mais secos.
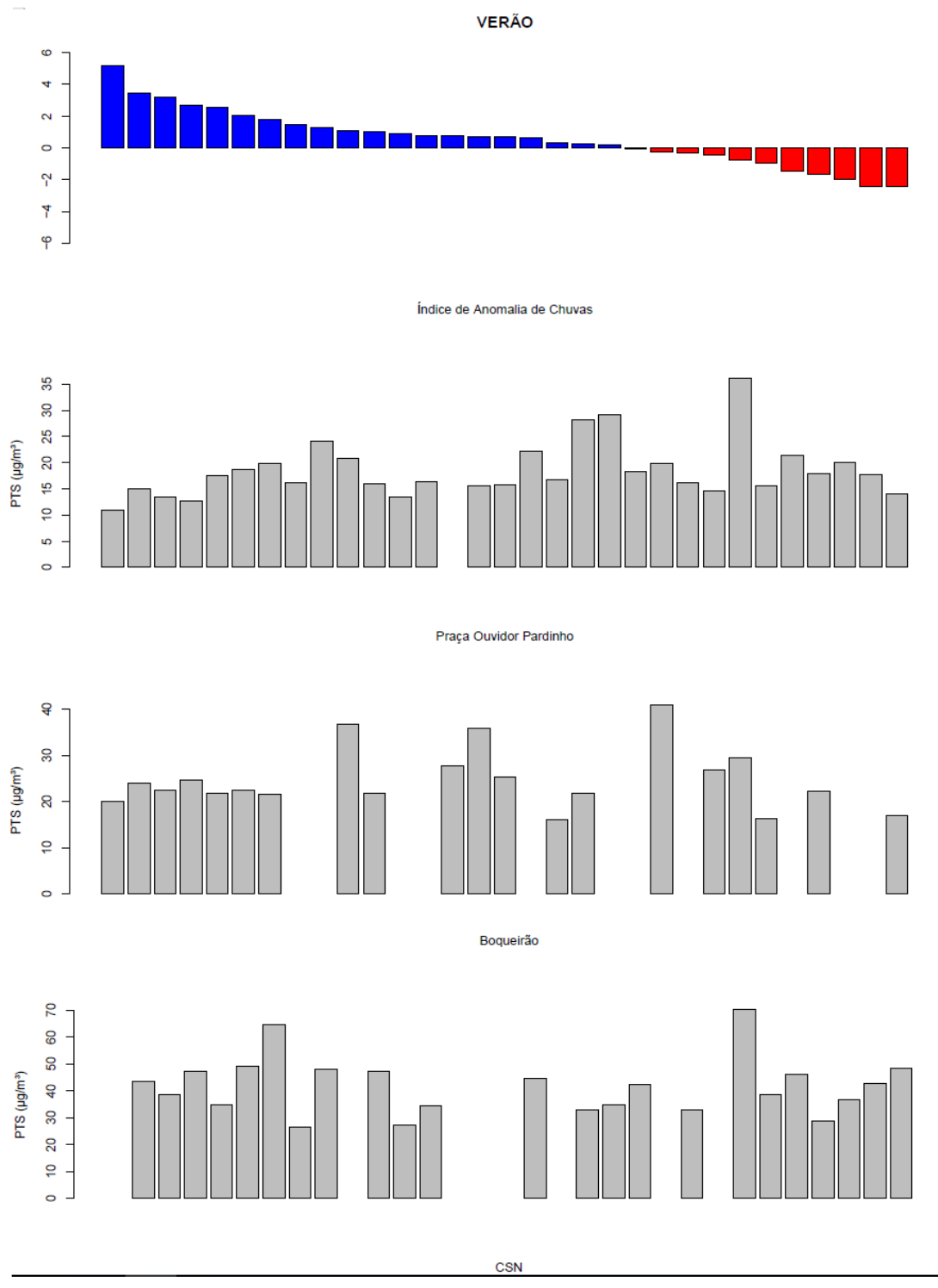

Figura 4 - Indice de Anomalia de Chuvas por ordem decrescente e Médias Mensais de PTS - Verão 2004 a 2015

DOI - 10.20396/sbgfa.v1i2017.2588 - ISBN 978-85-85369-16-3 


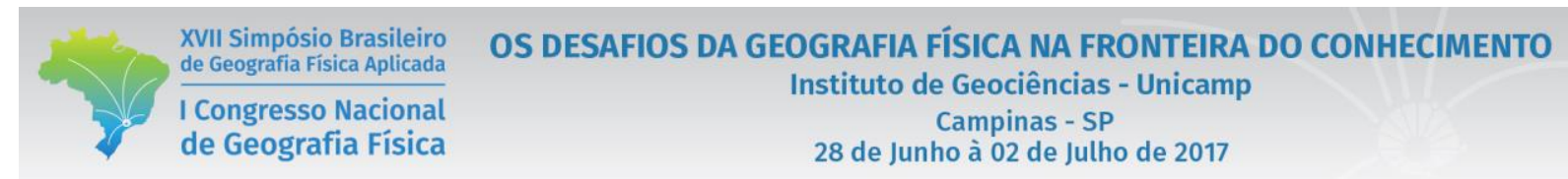

A figura 5 revela igual situação para os meses de Outono, (Março, Abril, Maio). Diferente do observado na Figura 4, neste caso prevalecem os meses com anomalia negativa de chuva, e novamente observa-se um aumento significativo nos valores médios de PTS à medida que o IAC diminui. Novamente observa-se que os maiores valores médios do poluente, nos três pontos de análise se sucederam em meses com IAC negativo.

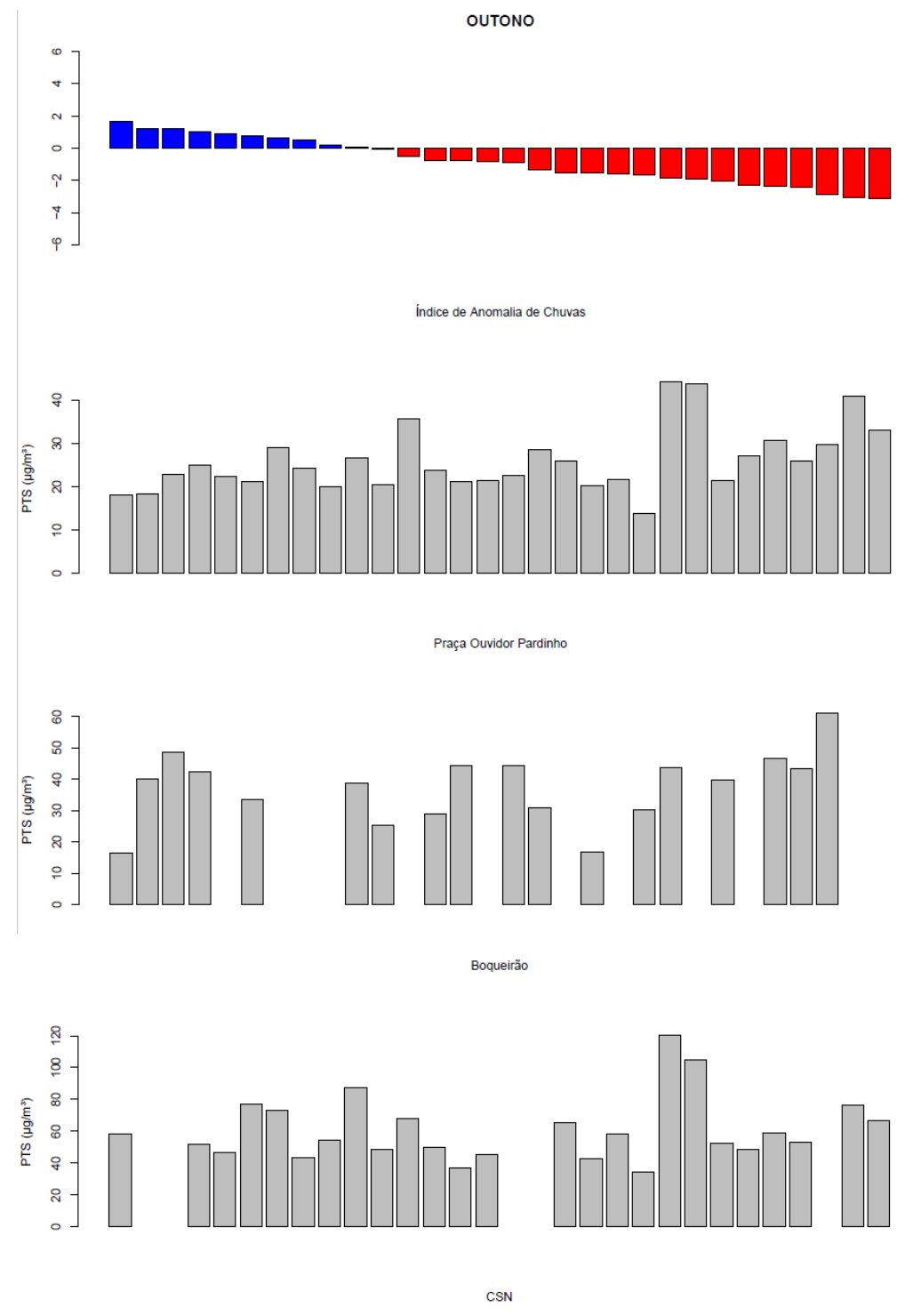

Figura 5 - Indice de Anomalia de Chuvas por ordem decrescente e Médias Mensais de PTS - Outono 2004 a 2015 


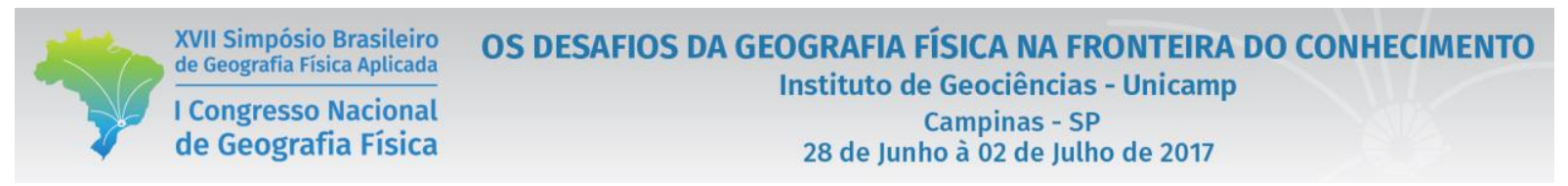

Para a estação de Inverno (Figura 6), o número de meses com anomalia negativa se acentua ainda mais, contudo, observa-se na estação Boqueirão, durante um mês com anomalia positiva, o registro de maior valor médio de PTS $\left(88,4 \mu \mathrm{g} / \mathrm{m}^{3}\right)$.

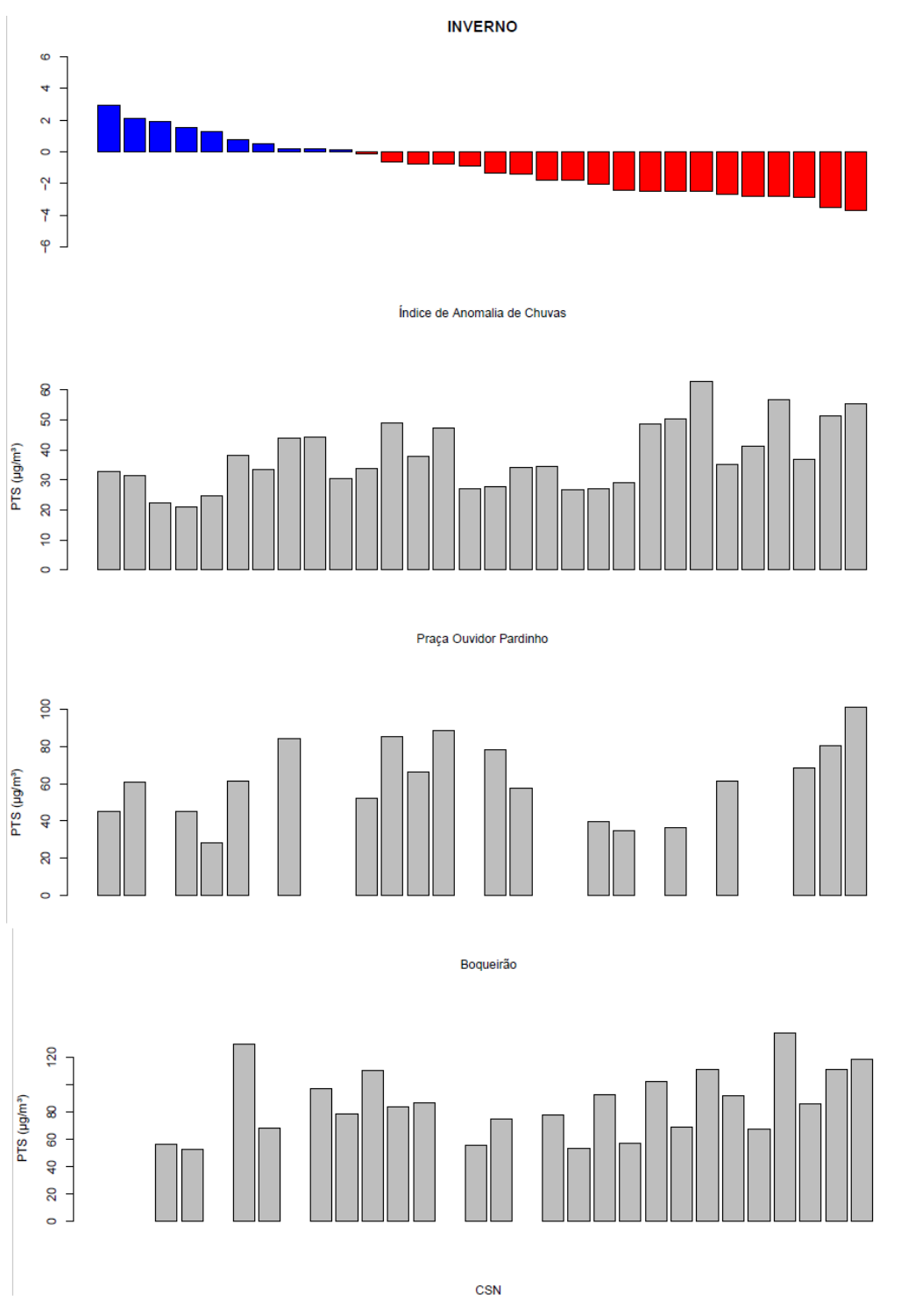

Figura 6 - Indice de Anomalia de Chuvas por ordem decrescente e Médias Mensais de PTS - Inverno 2004 a 2015

Durante a estação da Primavera, apontada pela Figura 7, o padrão observado foi semelhante às demais estações. Portanto, os maiores valores médios de PTS se sucedendo em meses com valores do IAC negativos. Ressalta-se que na estação Boqueirão, observou-se que o menor valor médio do poluente (16,8 $\mu \mathrm{g} / \mathrm{m}^{3}$ ) ocorreu em um mês com menor valor de anomalia de chuva. 
PRIMAVERA
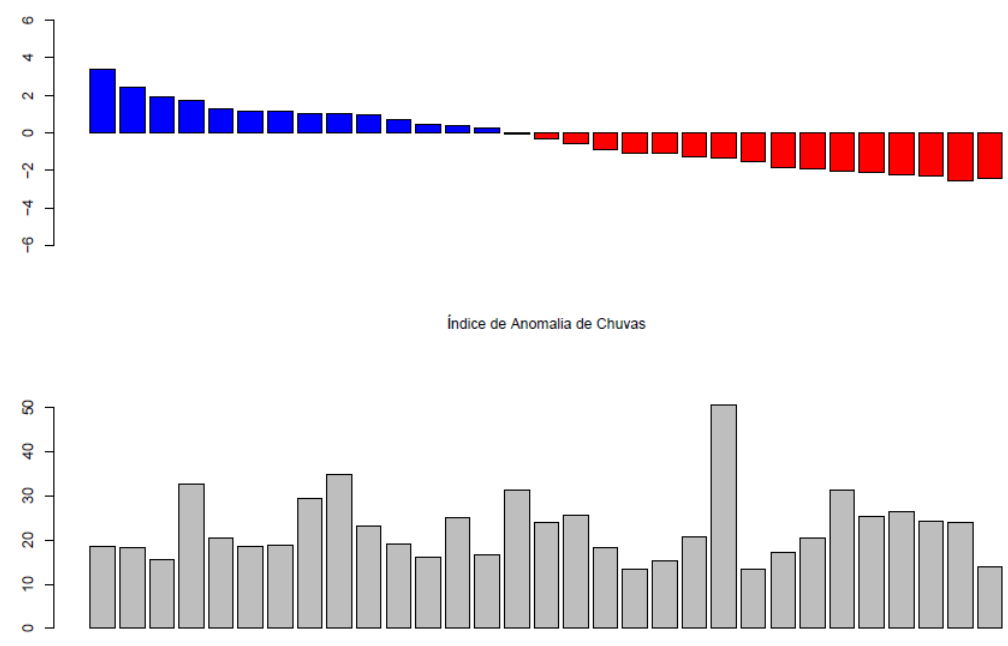

Praça Ouvidor Pardinho

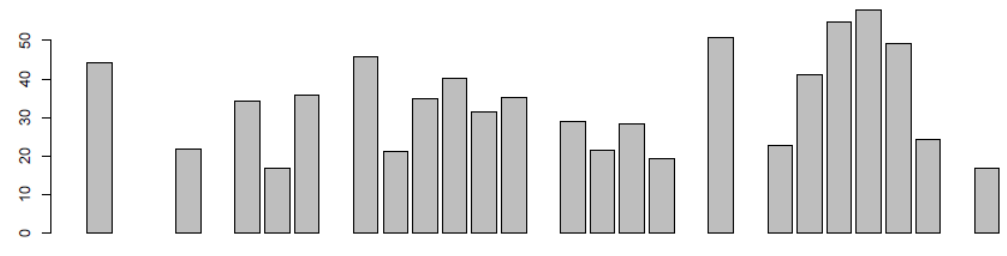

Boqueirão
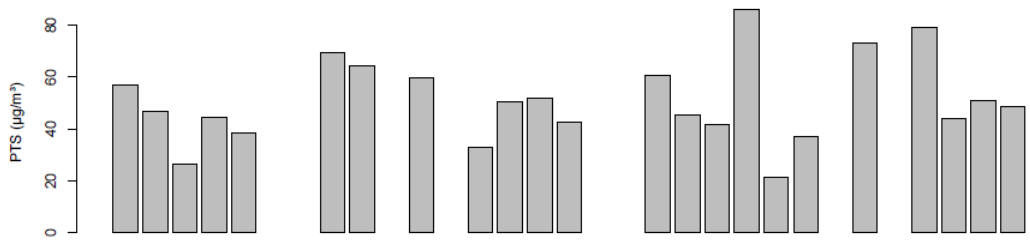

$\operatorname{csN}$

Figura 7 - Indice de Anomalia de Chuvas por ordem decrescente e Médias Mensais de PTS - Primavera 2004 a 2015

\section{Conclusões e Considerações Finais}

Os gráficos e calculos deflagrados ao longo deste trabalho revelaram uma relação inversa existente entre as anomalias de chuvas e os valores médios de Particulas Totais em Suspensão para a cidade de Curitiba. Sabe-se da relação entre chuva e umidade relativa do ar e dito poluente, conforme apontado por Kartal e Ozer (1998), contudo, observar sua relação com as anomalias de chuva fornece um maior detalhamento de tal relação, possibilitando um pequeno avanço nesta área de estudo. A análise sazonal fez-se necessária em 
função da ja dita sazonalidade do poluente. A titulo de exemplo, espera-se que em epocas de verão os valores de PTS sejam reduzidos em relação as de inverno, e isto independe dos valores do IAC.

Há de se levar em conta que o grande número de variaveis que compõe o sistema referente à qualidade do ar não permite que relações diretas sejam aferidas, portanto, não pode-se responsabilizar apenas os valores de chuva pela oscilação nos valores de poluição, dado que, outras variaveis climáticas como velocidade e direção dos ventos, umidade do ar e temperatura tambem interferem na dispersão.

Os aspectos meteorologicos compõe-se como condicionantes deste sistema e não como agentes determinantes. Entende-se que, em uma situação meteorologica totalmente favoravel ao acumulo de poluentes, se não houverem emissões, a qualidade do ar será boa, apesar do tempo desfavoravel, contudo, se forem observadas condições temporais favoraveis a dispersão, e ocorreram altos níveis de emissão, a qualidade do ar não será correspondente as condições meteorologicas.

Como uma área de estudo ainda pouca explorada no âmbito da geografia, faz-se necessário estudos cada vez mais detalhados envolvendo não apenas questões climáticas, mas tambem outros aspectos geoecologicos de igual importância na compreensão da dinâmica de dito problema ambiental.

\section{Bibliografia}

AKPINAR E., AKPINAR S., OZTOP H. Statistical analysis of meteorological factors and air pollution at winter months in Elazĭ̆ Turkey. Journal of Urban and Environmental Engineering, Vol. 3, N.1, p. 07-16, 2009

AYOADE, J.O. Introdução a Climatologia para os Trópicos, Editora Difel, São Paulo, 1986

CAstelhano, F. J.; MEndonCA, F. A. . Pollution de L'air Par les Particules Totales en Suspension (Tsp) a Curitiba (Bresil). Actes du XXIX Colloque de l'Association Internationale de Climatologie, Besançon. v. 1. p. 2732,2016

DANNI-OLIVEIRA, I.M, A cidade de Curitiba e a Poluição do ar, Tese de doutorado, USP, 2000

DERISIO, J.C. Introdução ao Controle de Poluição Ambiental, Ed. Oficina de Textos, São Paulo, 2012.

GUtJAhr,M.R., A Poluição do Ar em Paulínia (SP): Uma análise histórico-geográfica do clima, Tese de Doutorado, USP, 2002

HUFTY,A, Introduction a lá Climatalogie - Le rayonnement et la temperature, L'atmosphere, L'eau, Le Climat et L'activité Humaine, Laval, Le Presses de L'université Laval, 2001 
KARTAL,S. e OZER, U. Determination and Parameterization of Some Air Pollutants as a Function of Meteorological Parameters in Kayseri, Turkey, Journal of the Air \& Waste Management Association,V. 48, p. 853-859, 1998.

MCCORMAC,B.M., Introduction to the Scientific Study of Atmospheric Pollution, D. Reidel Publisinhg Company, 1971

MONTEIRO, C.A.F. Teoria e Clima Urbano. São Paulo: IGEO/USP, 1976.

ROOY, M. P V. A rainfall anomaly index independente of time and space. Notes. Weather Bureau of South Africa, v.14, p.43-48, 1965. 